\title{
Regulation of let-7 and its target oncogenes (Review)
}

\author{
XIRUI WANG ${ }^{*}$, LEI CAO $^{*}$, YINGYI WANG ${ }^{*}$, XIEFENG WANG, NING LIU and YONGPING YOU \\ Department of Neurosurgery, The First Affiliated Hospital of Nanjing Medical University, \\ Nanjing, Jiangsu 210029, P.R. China
}

Received October 20, 2011; Accepted February 1, 2012

DOI: 10.3892/ol.2012.609

\begin{abstract}
MicroRNAs (miRNAs) are highly evolutionarilyconserved non-coding small RNAs, which were first identified in Caenorhabditis elegans. Let-7 miRNA is involved in the regulation of gene expression in cells. Several novel factors and feedback loops involved in the regulation of the synthesis of let-7 have been identified and additional let-7 target genes have been found. Let-7 has also been shown to be significantly correlated with the occurrence and development of cancer and the results of preliminary studies suggest that it is involved in the regulation of oncogenic pathways in numerous types of tumors. Let-7 is, therefore, a potential molecular target for tumor therapy. Thus, this review examined let-7 and the correlation between let-7 and oncogenic pathways in cancer.
\end{abstract}

\section{Contents}

1. Introduction

2. Regulation of let-7 expression

3. Mechanisms of action

4. Target oncogenic signaling pathways of let-7

5. Conclusions

\section{Introduction}

MicroRNAs (miRNAs) are short single-stranded RNA molecules approximately 22 nucleotides in length. They are involved in the post-transcriptional regulation of gene expression, through binding to complementary sequences in the 3

Correspondence to: Dr Yongping You, Department of Neurosurgery, The First Affiliated Hospital of Nanjing Medical University, 300 Guangzhou Road, Nanjing, Jiangsu 210029, P.R. China

E-mail: yyp19@njmu.edu.cn

${ }^{*}$ Contributed equally

Abbreviations: miRNA, microRNA; 3' UTRs, 3' untranslated regions; NF, nuclear factor; SNP, single nucleotide polymorphism; RNase, ribonuclease

Key words: microRNA, let-7, regulation, cancer, regulatory circuit untranslated regions (3' UTRs) of target mRNA transcripts (1). miRNAs exist in three forms during their synthesis: primary miRNAs (pri-miRNAs), precursor miRNAs (pre-miRNAs) and mature miRNAs. Pri-miRNA contains a 5' cap and poly(A) tail and is first transcribed by RNA polymerase II as a long transcript. Following the processing of pri-miRNA by the RNase III enzyme Drosha in the nucleus, pre-miRNA is released, exported to the cytoplasm by exportin-5 and processed by the RNase III enzyme Dicer to produce a mature miRNA-miRNA duplex (2). Single-stranded mature miRNA is incorporated from the duplex into an RNA-induced silencing complex (RISC) where it mediates the silencing of target genes $(3,4)$.

In 2000, Reinhart et al identified a novel miRNA, let-7, which was able to implement and change the nematode phenotype during the later development of Caenorhabditis elegans (5). Numerous members of the let-7 family have been identified in various species and different members are found in different species (6). At present, 10 mature subtypes of the let-7 family have been identified in humans, including let-7a, let-7b, let-7c, let-7d, let-7e, let-7f, let-7g, let-7i, miR-98 and miR-202, in which mature let-7a and let-7f were produced by precursor sequences (let-7a-1, let-7a-2, let-7a-3; let-7f-1, let-7f-2). In normal physiology, let-7 is primarily involved in development, muscle formation, cell adhesion and gene regulation. The regulation of let-7 synthesis has been the subject of increasing attention and numerous proteins and factors have been shown to be correlated with let-7 family expression, including certain complete regulatory loops. Progress has also been made in understanding the mechanisms of action of let-7 miRNA. A number of studies have reported that let-7 is downregulated in numerous types of cancer, including lung cancer (7), gastric tumors (8), colon cancer (9) and Burkitt's lymphoma (10). Low levels of let-7 expression have been associated with the clinical postoperative survival of patients with lung cancer (7). The let-7 miRNA family is involved in the proliferation, apoptosis and invasion of cancer cells. Oncogenes and their signaling pathways are a potential connection between the level of expression of let-7 and the biological characteristics of tumor cells. This review explored the regulation of let-7 expression and its mechanisms of action, as well as its correlation with oncogenic pathways in tumors.

\section{Regulation of let-7 expression}

Let-7 is found in Caenorhabditis elegans and appears to act as a key regulator of temporal patterning, coordinating 


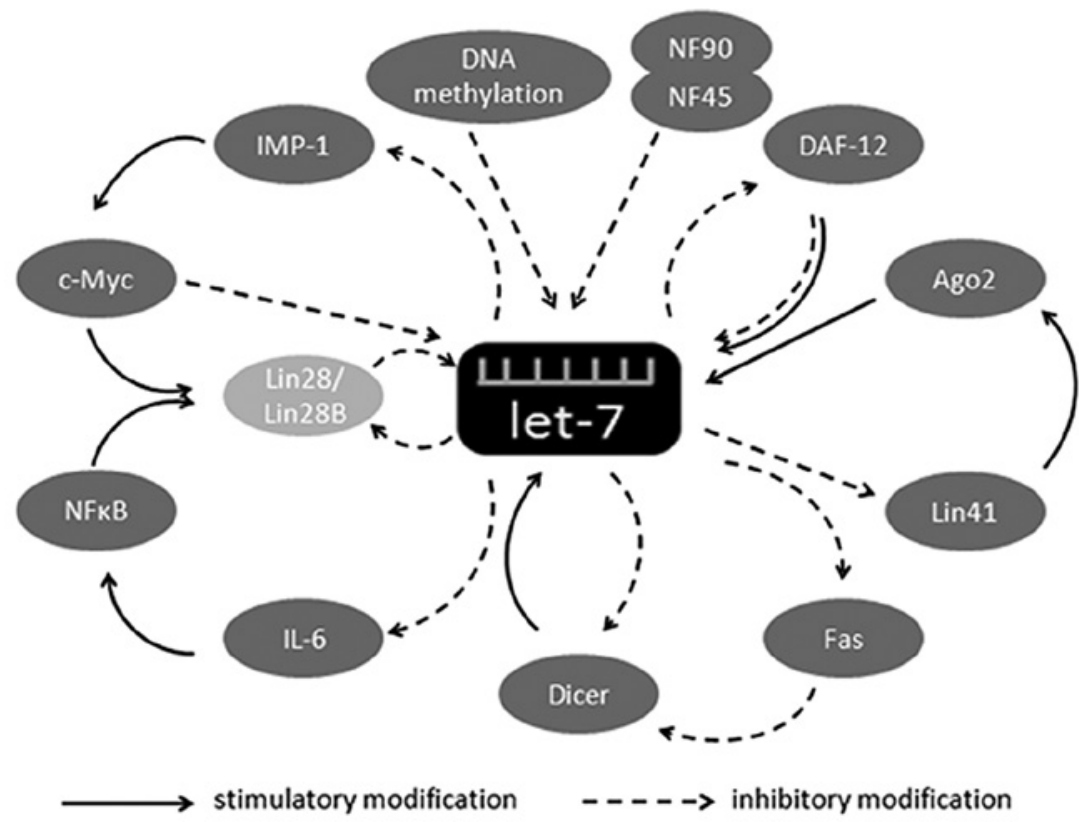

Figure 1. Regulation of let-7 expression.

developmental timing across tissues (11). As a conserved sequence, its expression and function as a regulator of cell differentiation and proliferation have been confirmed in animal and human cells (12-15). In addition to regulating the differentiation and proliferation of normal cells, let-7 has also been found to be involved in inhibiting the growth of tumor cells $(16,17)$. The regulation of let-7 expression has become increasingly important in light of its involvement in tumor suppression. The expression of let-7 is regulated at various stages of its biogenesis and the regulation process involves numerous factors and regulatory circuits (Fig. 1). However, although some regulatory circuits have been demonstrated, others remain theoretical.

Lin 28 and Lin28B. Reinhart et al found that the activity of let-7 was affected by mutations in $\operatorname{Lin} 28$ (5). Lin28 and Lin28B have been shown to act as post-transcriptional repressors of let-7 biogenesis, by binding to the loop portion of the pri-let-7 hairpin and the stem of pre-let-7 to inhibit the binding of Drosha or Dicer, thereby inhibiting its processing $(18,19)$. The mechanism of Lin 28 binding to the terminal loop region of let $-7 \mathrm{~g}$ has been elucidated (20) and the cold-shock and zinc-finger domains in Lin28 were shown to be required for pre-let-7 binding, resulting in $>90 \%$ inhibition of let $7 \mathrm{~g}$ processing upon the upregulation of Lin28. Lin28 is also considered to be necessary and sufficient to block the microprocessor-mediated cleavage of pri-let-7 miRNAs (18), as the ectopic expression of Lin 28 completely prevented the processing of pri-let-7a and pri-let-7g, whereas the processing of pri-miR-15a and pri-miR122 were largely unaffected. In addition, the transfection of Lin28 cDNA decreased the endogenous levels of mature let-7 family members, but had no effect on the levels of endogenous mature miR-21 (18).

A novel mechanism whereby Lin28/Lin28B blocks let-7 processing, other than by Drosha/Dicer inhibition, has been identified. Lin28 was shown to be able to directly regulate let-7 synthesis by targeting pre-let-7 and affecting its terminal uridylation (21); Lin28 mediates the terminal uridylation of pre-let-7, thus diverting Dicer processing and irreversibly re-routing pre-let-7 to a degradation pathway. Three enzymes have been reported to be involved in the terminal uridylation progress. Zcchc11 is a terminal uridylyl transferase (TUTase) and is required by Lin 28 for the mediation of pre-let-7 uridylation and the subsequent blockade of let-7 processing in mouse embryonic stem cells (22). TUT4 is recruited by Lin28 to pre-let-7 via the recognition of a tetranucleotide sequence motif (GGAG) in the terminal loop. TUT4 in turn adds an oligouridine tail to pre-let-7 to block Dicer processing (23). PUP-2 interacts directly with Lin28 to regulate the stability of Lin28-blockaded let-7 pre-miRNA to suppress the action of Dicer and contribute to the Lin28-stimulated uridylation of let-7 pre-miRNA, preventing its maturation in Caenorhabditis elegans (24).

DNA methylation. It has been suggested that DNA methylation is correlated with human tumorigenesis. The hyper- or hypomethylation of $\mathrm{CpG}$ islands, often observed in tumor cells, results in the silencing of genes and is significant in tumor development (25-27). The results of certain studies suggest that some miRNA genes are methylated, with consequent effects on miRNA expression (28-30). The expression of let-7 has been reported to be regulated by DNA methylation. The human let-7a-3 gene is located on chromosome 22q13.31 and is associated with a $\mathrm{CpG}$ island, which is methylated by the DNA methyltransferases DNMT1 and DNMT3B. Let-7a-3 is methylated in normal lung samples, with a similar methylation pattern to that observed in other human tissues. The hypomethylation of let-7a-3 was found to increase the level of expression of miRNA and inhibit the growth of tumor cells in lung adenocarcinomas (31). Hypermethylation resulted in the downregulation of let-7a-3 in epithelial ovarian cancer and this low level of expression of let-7a-3 in epithelial ovarian cancer was associated with a poor prognosis (32). 
Nuclear factor 90 and nuclear factor 45. Nuclear factor (NF) 90 and NF45 belong to the larger Drosha complex family, which is needed for the production of pre-miRNA from pri-miRNA. The overexpression of NF90 and NF45 has been shown to be associated with the level of pri-miRNA. The NF90-NF45 complex, rather than either factor alone, binds the majority of pri-miRNAs with a higher affinity for pri-let-7a-1 than the DGCR8-Drosha complex, which also binds to pri-miRNAs. The NF90-NF45 complex may thus inhibit the processing of pri-miRNA by the DGCR8-Drosha complex. NF90-NF45 also showed a higher binding affinity for pri-let-7a-1 than for pri-miR-21 (33).

Regulatory circuits involved in let-7 expression. The regulation of let-7 biogenesis is complex and involves numerous regulatory factors, including a number of factors that control let-7 expression via regulatory loops. These loops may be divided into two categories: Lin28-dependent and Lin28independent. The regulatory feedback loops that depend on Lin28 are all positive and include the NFkB-Lin28-let-7interleukin (IL)-6-NFKB, Lin28-let-7-insulin-like growth factor II mRNA-binding protein 1 (IMP1)-c-Myc-Lin28 and Lin28-let-7-Lin28 loops.

Inflammation is clinically linked to cancer and certain inflammation-related molecules, including $\mathrm{NF \kappa B}$, have been demonstrated to be key in this association. A regulatory feedback loop controlling let-7 expression and including NFKB has been identified and may aid the elucidation of the mechanistic link between inflammation and cancer. NFKB directly activates Lin 28 transcription and rapidly reduces let-7 levels. Let-7 may then directly inhibit IL-6 expression, which may activate $\mathrm{NF \kappa B}$, thereby completing a positive feedback loop (34).

As a target oncogene of let-7, c-Myc may be directly regulated by IMP1, which has been shown to be directly and negatively regulated by let-7 $(35,36)$. In addition, c-Myc was shown to be able to directly transactivate Lin28B, a Lin28 homolog, to inhibit let-7 expression. The activation of Lin28B was observed to be necessary and sufficient for Myc-mediated let-7 expression $(37,38)$. It is also possible, however, that Myc regulates let-7 directly (39).

Besides indirectly regulating the expression of Lin 28 , let-7 may also affect Lin2 8 directly; the binding of let- 7 to the $3^{\prime}$ UTR of Lin28/Lin28B transcripts represses the expression of Lin28/ Lin28B (38). As discussed, Lin28 is a classical direct inhibitor of let-7, creating a double-negative regulatory loop for let-7.

Certain loops, however, do not require Lin28, including the DAF-12-let-7-DAF-12, Ago2-let-7-Lin41-Ago2, Dicer-let-7Dicer and Fas-Dicer-let-7-Fas loops.

The DAF-12-let-7-DAF-12 loop consists only of DAF-12 and let-7. DAF-12 is able to directly regulate the transcription of let-7 either positively (as liganded DAF-12) or negatively (as unliganded DAF-12). At the same time, let-7 can mediate the expression of DAF-12 by binding its 3' UTR (40).

Ago2, as the RISC slicer providing the RNase activity required to cleave target mRNAs for miRNA, may also directly bind let-7a or generate an additional miRNA precursor to stabilize and enhance mature let-7a (41). Lin41, a target gene of let-7, has been reported to negatively regulate Ago2 levels (42).

Dicer is a classical enzyme which is essential for all miRNA synthesis processes. Let-7 has been reported to directly target the miRNA-processing enzyme Dicer within its coding sequence, thus establishing another autoregulatory negative feedback loop for let-7 (43). However, let-7b is downregulated when Dicer is overexpressed in oral cancer cells (44), indicating a double-negative regulatory loop for let- $7 \mathrm{~b}$ and Dicer in oral cancer cells.

Fas (also termed APO-1 or CD95) was first identified by Yonehara et al in 1989 and was considered to be a novel cell surface protein antigen that differed from the tumor necrosis factor (TNF) receptor, but was able to mediate the cytolytic activity of TNF (45). Fas was found to induce apoptosis by binding to specific ligands, including Fas ligand (FasL), TNF- $\alpha$ and Fas-specific monoclonal antibody CH11 (mAb CH11) in sensitive cells $(46,47)$. The apoptosis-inducing ability of Fas has since been used to inhibit the growth of tumor cells (48). Fas has been reported to be regulated by let-7/miR-98 in T cells (49) and this observation had been confirmed in human colon carcinoma. Activated Fas is able to inhibit Dicer activation, reducing the levels of mature let-7 miRNA (50).

These regulatory circuits maintain the balance of the let-7 levels in a normal organism. The level of expression of let-7 is affected when factors which take part in the regulatory circuits are altered. Changes in the level of expression of let-7 may induce normal and abnormal responses. Therefore, the single nucleotide polymorphisms (SNPs) of tumor suppressor miRNA biogenesis genes are considered to be high-risk factors for cancer $(51,52)$. An SNP of the Lin28 gene, rs3811463, located near the let-7 binding site, resulted in the weakened repression of Lin28 mRNA induced by let-7 and the downregulation of let-7 expression via the let-7-Lin28 double negative feedback loop. This SNP was therefore considered to raise the risk of tumorigenesis in breast cancer (53).

\section{Mechanisms of action}

The classical mechanism of let-7 action involves its binding to the $3^{\prime}$ UTR of target mRNAs to regulate their expression. However, in addition to this classical mechanism, let-7 may act in other ways.

Let-7a caused identical responses when it was targeted to the 5' or 3' UTRs of mRNAs containing internal ribosome entry sites (54), indicating that let-7 is able to act through binding to sites other than the $3^{\prime}$ UTR of target mRNAs. Furthermore, let-7 binds not only to untranslated or non-coding regions, but is also able to bind directly to coding regions to restrict target mRNAs (43).

The mechanisms of let-7 action on mRNAs remain under debate. Let-7a may repress the translation of target mRNAs by binding to and inhibiting translating polyribosomes (55). Deadenylation is another route whereby let-7 may inhibit translation and contribute to mRNA decay, with the translational repression function being more prominent than mRNA decay. However, deadenylation alone is not sufficient to effect full mRNA repression (56).

\section{Target oncogenic signaling pathways of let-7}

c-Myc, ras, high-mobility group A (HMGA), Janus protein tyrosine kinase (JAK), signal transducer and activator of tran- 
scription 3 (STAT3) and NIRF are oncogenes that are critical in tumorigenesis, proliferation and invasion and which are targeted by let-7. These oncogenes activate or upregulate the expression of their downstream target proteins, which directly regulate the cell cycle, apoptosis and cell adhesion. Let-7 may thus act as a tumor suppressor through the inhibition of these oncogenic signaling pathways.

Regulation of the ras oncogene. Ras is associated with numerous downstream signaling pathways, including Ras/ $\mathrm{Raf} /$ mitogen-activated protein kinase, Ras/phosphoinositide 3-kinase/Aktand Ras/Rho/Ral.Following activation by complex signaling cascades, Ras is able to bind to numerous effectors to trigger further signaling cascades, which in turn modulate cell processes including growth, survival, migration, differentiation and death. Let-7 is expressed in normal adult lung tissues (35), but has a lower level of expression in lung tumors that express high levels of Ras protein (7). This inverse correlation between let-7 and Ras suggests a causal relationship. The three human ras genes (H-ras, K-ras and N-ras) have let-7-complementary sites in their $3^{\prime}$ UTRs (57). SNPs in the let-7 complementary sites in the 3' UTR of K-ras resulted in increased levels of $\mathrm{K}$-ras and poor prognosis of patients with lung and breast cancer (58-60). Chin et al found that tumors which contained a variant allele had lower let-7 levels than those without a variant allele and hypothesized that SNPs in the let-7 binding site of the K-ras 3' UTR reduce the levels of let-7 through a feedback loop (59). The overexpression of let-7 resulted in a lower level of expression of the Ras protein, a reduction in cell proliferation and migration in glioma and lung cancer cells and a decrease in the size of gliomas and lung tumors in nude mice $(61,62)$. These results suggest that let-7 directly and negatively mediates the expression of the Ras protein (H-Ras, K-Ras and N-Ras) by binding to 3' UTR complementary sites. The downstream proteins in Ras signaling pathways should thus be downregulated when let-7 is overexpressed in cancer cells, resulting in changes in cell function.

HMGA as a target oncogene of let-7. HMGA proteins (HMGA1a, HMGA1b and HMGA2) are polypeptides of $~ 100$ amino acid residues characterized by a modular sequence organization, with three highly positively-charged regions, termed AT hooks, that bind the minor groove of AT-rich DNA stretches. These proteins regulate gene expression by altering the structure of chromatin or by direct protein-protein interactions with transcription factors (63). As an oncogene, the overexpression of the HMGA2 protein has been observed in a number of tumors (64-68). It has been suggested that HMGA2 expression is controlled by negatively-acting regulatory elements within the $3^{\prime}$ UTR. The overexpression of HMGA2 in tumors may thus occur due to this regulatory element being unable to bind effectively to the 3' UTR of HMGA2, which is reduced or absent in tumor cells (69). The level of let-7 expression is significantly higher in gastric cancer patients with a high HMGA2 expression than in those with low a HMGA2 expression (70). Furthermore, HMGA2 expression was found to be downregulated when let-7 was overexpressed (71). These results demonstrate that let- 7 negatively mediates the expression of the oncogene HMGA2 by binding to its 3' UTR and directly suppressing its expression (72).
Myc oncogene and pathway. The proto-oncogene Myc is frequently activated in tumors (73). Activated Myc increases cell growth, division and survival by increasing the synthesis of its target proteins, some of which are involved in the regulation of the cell cycle and apoptosis (74). The overexpression of let-7a was found to downregulate Myc mRNA and protein $(9,10)$ and it has been suggested that let-7 regulates Myc expression directly by binding to its 3' UTR. However, let-7 also affects the cell cycle by directly mediating certain downstream proteins [cyclin D1 and cyclin-dependent kinase (CDK) 6] in the Myc oncogene signaling pathway $(75,76)$.

JAK-STAT3 pathway. JAK is a member of the protein tyrosine kinase family. Activated JAK activates STATs, which are commonly expressed in all tissues and cells in the human body. STAT activation is involved in the genesis, differentiation and apoptosis of cells and inflammation, cancer and the immune response (77). STAT3 is a member of the STAT family. The JAK-STAT3 pathway is activated in a number of types of tumors and has been confirmed to be correlated with cancer (78-80). STAT3 was found to be a target of let-7a, mediating cell proliferation in HepG2 cells (81). Let-7 may thus also regulate the activity of tumor cells by targeting the JAK-STAT3 pathway.

NIRF oncogene and let-7. The nucleic protein NIRF is encoded by the UHRF2 gene, which is a member of the UHRF oncogene family. NIRF contains a ubiquitin-like domain and a ring-finger structural domain which are essential for UHRF E3 ligase activity to regulate DNA methylation $(82,83)$. DNA damage may activate a p53-dependent checkpoint pathway resulting in the induction of p21WAF1 expression and subsequent cell cycle arrest at the G1/S phase, through the inhibition of CDK activity and DNA replication. A reduction in the levels of UHRF family members has been reported to correlate with p21WAF1 expression (84). Let-7a was found to suppress NIRF expression via binding to the 3' UTR of NIRF mRNA and enhance p21WAF1 expression in A549 lung cancer cells (85), indicating that let-7a may regulate the cell cycle via a NIRF/ p53/p21/CDK signaling pathway.

\section{Conclusions}

Let-7 miRNA has been the subject of increasing interest as a potential therapeutic target in cancer. Let-7 is able to suppress tumor proliferative activities and survival by negatively mediating a number of oncogenes and by affecting key regulators of the cell cycle, cell differentiation and apoptotic pathways. The upregulation of let-7 is expected to provide an effective cancer therapy. Therefore, although significant progress has been made in understanding the regulation of let-7 synthesis and its role in oncogenic signaling pathways, its regulation in normal and malignant cells and the mechanisms whereby it controls cell proliferation and survival require further elucidation. Additional investigations are needed to enable the clinical application of let-7 regulation to cancer suppression.

\section{Acknowledgements}

This study was supported by the China Natural Science Foundation (81072078, 81101901 and 81172389), the Natural 
Science Foundation of Jiangsu Province (201123808 and 2010580), Jiangsu Province's Key Provincial Talents Program (RC2011051), Jiangsu Province's Key Discipline of Medicine (XK201117), Program for Development of Innovative Research Team in the First Affiliated Hospital of NJMU, a project funded by the Priority Academic Program Development of Jiangsu Higher Education Institutions, and National High Technology Research and Development Program 863 (2012AA02A508).

\section{References}

1. Nilsen TW: Mechanisms of microRNA-mediated gene regulation in animal cells. Trends Genet 23: 243-249, 2007.

2. Hutvágner G, McLachlan J, Pasquinelli AE, Bálint E, Tuschl T and Zamore PD: A cellular function for the RNA-interference enzyme Dicer in the maturation of the let-7 small temporal RNA. Science 293: 834-838, 2001.

3. Kim VN, Han J and Siomi MC: Biogenesis of small RNAs in animals. Nat Rev Mol Cell Biol 10: 126-139, 2009.

4. Carthew RW and Sontheimer EJ: Origins and mechanisms of miRNAs and siRNAs. Cell 136: 642-655, 2009.

5. Reinhart BJ, Slack FJ, Basson M, Pasquinelli AE, Bettinger JC Rougvie AE, Horvitz HR and Ruvkun G: The 21-nucleotide let-7 RNA regulates developmental timing in Caenorhabditis elegans. Nature 403: 901-906, 2000.

6. Roush S and Slack FJ: The let-7 family of microRNAs. Trends Cell Biol 18: 505-516, 2008.

7. Takamizawa J, Konishi H, Yanagisawa K, Tomida S, Osada H, Endoh H, Harano T, Yatabe Y, Nagino M, Nimura Y, et al: Reduced expression of the let-7 microRNAs in human lung cancers in association with shortened postoperative survival. Cancer Res 64: 3753-3756, 2004.

8. Zhang HH, Wang XJ, Li GX, Yang E and Yang NM: Detection of let-7a microRNA by real-time PCR in gastric carcinoma. World J Gastroenterol 13: 2883-2888, 2007.

9. Akao Y, Nakagawa Y and Naoe T: Let-7 microRNA functions as a potential growth suppressor in human colon cancer cells. Biol Pharm Bull 29: 903-906, 2006.

10. Sampson VB, Rong NH, Han J, Yang Q, Aris V, Soteropoulos P, Petrelli NJ, Dunn SP and Krueger LJ: MicroRNA let-7a downregulates MYC and reverts MYC-induced growth in Burkitt lymphoma cells. Cancer Res 67: 9762-9770, 2007.

11. Grosshans H, Johnson T, Reinert KL, Gerstein M and Slack FJ: The temporal patterning microRNA let-7 regulates several transcription factors at the larval to adult transition in C. elegans. Dev Cell 8: 321-330, 2005.

12. Sokol NS, Xu P, Jan YN and Ambros V: Drosophila let-7 microRNA is required for remodeling of the neuromusculature during metamorphosis. Genes Dev 22: 1591-1596, 2008.

13. Caygill EE and Johnston LA: Temporal regulation of metamorphic processes in Drosophila by the let-7 and miR-125 heterochronic microRNAs. Curr Biol 18: 943-950, 2008.

14. Thomson JM, Parker J, Perou CM and Hammond SM: A custom microarray platform for analysis of microRNA gene expression. Nat Methods 1: 47-53, 2004.

15. Landgraf P, Rusu M, Sheridan R, Sewer A, Iovino N, Aravin A, Pfeffer S, Rice A, Kamphorst AO, Landthaler M, et al: A mammalian microRNA expression atlas based on small RNA library sequencing. Cell 129: 1401-1414, 2007.

16. Esquela-Kerscher A and Slack FJ: Oncomirs - microRNAs with a role in cancer. Nat Rev Cancer 6: 259-269, 2006.

17. Chang TC and Mendell JT: MicroRNAs in vertebrate physiology and human disease. Annu Rev Genomics Hum Genet 8: 215-239, 2007.

18. Viswanathan SR, Daley GQ and Gregory RI: Selective blockade of microRNA processing by Lin28. Science 320: 97-100, 2008.

19. Newman MA, Thomson JM and Hammond SM: Lin-28 interaction with the let-7 precursor loop mediates regulated microRNA processing. RNA 14: 1539-1549, 2008.

20. Piskounova E, Viswanathan SR, Janas M, LaPierre RJ, Daley GQ, Sliz P and Gregory RI: Determinants of microRNA processing inhibition by the developmentally regulated RNA-binding protein Lin28. J Biol Chem 283: 21310-21314, 2008.

21. Heo I, Joo C, Cho J, Ha M, Han J and Kim VN: Lin 28 mediates the terminal uridylation of let-7 precursor microRNA. Mol Cell 32: $276-284,2008$
22. Hagan JP, Piskounova E and Gregory RI: Lin 28 recruits the TUTase Zcchc11 to inhibit let-7 maturation in mouse embryonic stem cells. Nat Struct Mol Biol 16: 1021-1025, 2009.

23. Heo I, Joo C, Kim YK, Ha M, Yoon MJ, Cho J, Yeom KH, Han J and Kim VN: TUT4 in concert with Lin28 suppresses microRNA biogenesis through pre-microRNA uridylation. Cell 138: 696-708, 2009.

24. Lehrbach NJ, Armisen J, Lightfoot HL, Murfitt KJ, Bugaut A, Balasubramanian S and Miska EA: LIN-28 and the poly(U) polymerase PUP-2 regulate let-7 microRNA processing in Caenorhabditis elegans. Nat Struct Mol Biol 16: 1016-1020, 2009.

25. Jones PA and Baylin SB: The fundamental role of epigenetic events in cancer. Nat Rev Genet 3: 415-428, 2002.

26. Ehrlich M: DNA methylation in cancer: too much, but also too little. Oncogene 21: 5400-5413, 2002.

27. Esteller M: Relevance of DNA methylation in the management of cancer. Lancet Oncol 4: 351-358, 2003.

28. Lujambio A, Ropero S, Ballestar E, Fraga MF, Cerrato C, Setien F, Casado S, Suarez-Gauthier A, Sanchez-Cespedes M, Git A, et al: Genetic unmasking of an epigenetically silenced microRNA in human cancer cells. Cancer Res 67: 1424-1429, 2007.

29. Saito Y, Liang G, Egger G, Friedman JM, Chuang JC, Coetzee GA and Jones PA: Specific activation of microRNA-127 with downregulation of the proto-oncogene BCL6 by chromatin-modifying drugs in human cancer cells. Cancer Cell 9: 435-443, 2006.

30. Yoshitomi T, Kawakami K, Enokida H, Chiyomaru T, Kagara I, Tatarano S, Yoshino H, Arimura H, Nishiyama K, Seki N and Nakagawa M: Restoration of miR-517a expression induces cell apoptosis in bladder cancer cell lines. Oncol Rep 25: 1661-1668, 2011.

31. Brueckner B, Stresemann C, Kuner R, Mund C, Musch T, Meister M, Sültmann H and Lyko F: The human let-7a-3 locus contains an epigenetically regulated microRNA gene with oncogenic function. Cancer Res 67: 1419-1423, 2007.

32. Lu L, Katsaros D, de la Longrais IA, Sochirca O and Yu H: Hypermethylation of let-7a-3 in epithelial ovarian cancer is associated with low insulin-like growth factor-II expression and favorable prognosis. Cancer Res 67: 10117-10122, 2007.

33. Sakamoto S, Aoki K, Higuchi T, Todaka H, Morisawa K, Tamaki N, Hatano E, Fukushima A, Taniguchi T and Agata Y: The NF90-NF45 complex functions as a negative regulator in the micro RNA processing pathway. Mol Cell Biol 29: 3754-3769, 2009.

34. Iliopoulos D, Hirsch HA and Struhl K: An epigenetic switch involving NF-kappaB, Lin28, Let-7 microRNA, and IL6 links inflammation to cell transformation. Cell 139: 693-706, 2009.

35. Boyerinas B, Park SM, Shomron N, Hedegaard MM, Vinther J, Andersen JS, Feig C, Xu J, Burge CB and Peter ME: Identification of let-7-regulated oncofetal genes. Cancer Res 68: 2587-2591, 2008.

36. Ioannidis P, Mahaira LG, Perez SA, Gritzapis AD, Sotiropoulou PA, Kavalakis GJ, Antsaklis AI, Baxevanis CN and Papamichail M: CRD-BP/IMP1 expression characterizes cord blood CD34+ stem cells and affects c-myc and IGF-II expression in MCF-7 cancer cells. J Biol Chem 280: 20086-20093, 2005.

37. Chang TC, Zeitels LR, Hwang HW, Chivukula RR, Wentzel EA, Dews M, Jung J, Gao P, Dang CV, Beer MA, et al: Lin-28B transactivation is necessary for Myc-mediated let-7 repression and proliferation. Proc Natl Acad Sci USA 106: 3384-3389, 2009.

38. Dangi-Garimella S, Yun J, Eves EM, Newman M, Erkeland SJ, Hammond SM, Minn AJ and Rosner MR: Raf kinase inhibitory protein suppresses a metastasis signalling cascade involving LIN28 and let-7. EMBO J 28: 347-358, 2009.

39. Chang TC, Yu D, Lee YS, Wentzel EA, Arking DE, West KM, Dang CV, Thomas-Tikhonenko A and Mendell JT: Widespread microRNA repression by Myc contributes to tumorigenesis. Nat Genet 40: 43-50, 2008.

40. Hammell CM, Karp X and Ambros V: A feedback circuit involving let-7-family miRNAs and DAF-12 integrates environmental signals and developmental timing in Caenorhabditis elegans. Proc Natl Acad Sci USA 106: 18668-18673, 2009.

41. Diederichs S and Haber DA: Dual role for argonautes in microRNA processing and posttranscriptional regulation of microRNA expression. Cell 131: 1097-1108, 2007.

42. Rybak A, Fuchs H, Hadian K, Smirnova L, Wulczyn EA, Michel G, Nitsch R, Krappmann D and Wulczyn FG: The let-7 target gene mouse lin-41 is a stem cell specific E3 ubiquitin ligase for the miRNA pathway protein Ago2. Nat Cell Biol 11: 1411-1420, 2009. 
43. Forman JJ, Legesse-Miller A and Coller HA: A search for conserved sequences in coding regions reveals that the let-7 microRNA targets Dicer within its coding sequence. Proc Natl Acad Sci USA 105: 14879-14884, 2008.

44. Jakymiw A, Patel RS, Deming N, Bhattacharyya I, Shah P, Lamont RJ, Stewart CM, Cohen DM and Chan EK: Overexpression of dicer as a result of reduced let-7 microRNA levels contributes to increased cell proliferation of oral cancer cells. Genes Chromosomes Cancer 49: 549-559, 2010.

45. Yonehara S, Ishii A and Yonehara M: A cell-killing monoclonal antibody (anti-Fas) to a cell surface antigen co-downregulated with the receptor of tumor necrosis factor. J Exp Med 169: 1747-1756, 1989.

46. Peter ME, Budd RC, Desbarats J, Hedrick SM, Hueber AO, Newell MK, Owen LB, Pope RM, Tschopp J, Wajant H, Wallach D, et al: The CD95 receptor: apoptosis revisited. Cell 129: 447-450, 2007.

47. Barnhart BC, Legembre P, Pietras E, Bubici C, Franzoso G and Peter ME: CD95 ligand induces motility and invasiveness of apoptosis-resistant tumor cells. EMBO J 23: 3175-3185, 2004.

48. Gordon N and Kleinerman ES: Aerosol therapy for the treatment of osteosarcoma lung metastases: targeting the Fas/FasL pathway and rationale for the use of gemcitabine. J Aerosol Med Pulm Drug Deliv 23: 189-196, 2010.

49. Wang S, Tang Y, Cui H, Zhao X, Luo X, Pan W, Huang X and Shen N: Let-7/miR-98 regulate Fas and Fas-mediated apoptosis. Genes Immun 12: 149-154, 2011

50. Geng L, Zhu B, Dai BH, Sui CJ, Xu F, Kan T, Shen WF and Yang JM: A let-7/Fas double-negative feedback loop regulates human colon carcinoma cells sensitivity to Fas-related apoptosis. Biochem Biophys Res Commun 408: 494-499, 2011.

51. Liang D, Meyer L, Chang DW, Lin J, Pu X, Ye Y, Gu J, Wu X and $\mathrm{Lu} \mathrm{K}$ : Genetic variants in microRNA biosynthesis pathways and binding sites modify ovarian cancer risk, survival, and treatment response. Cancer Res 70: 9765-9776, 2010.

52. Permuth-Wey J, Kim D, Tsai YY, Lin HY, Chen YA, Barnholtz-Sloan J, Birrer MJ, Bloom G, Chanock SJ, Chen Z, et al: LIN28B polymorphisms influence susceptibility to epithelial ovarian cancer. Cancer Res 71: 3896-3903, 2011.

53. Chen AX, Yu KD, Fan L, Li JY, Yang C, Huang AJ and Shao ZM: Germline genetic variants disturbing the Let-7/LIN28 double-negative feedback loop alter breast cancer susceptibility. PLoS Genet 7: e1002259, 2011.

54. Lytle JR, Yario TA and Steitz JA: Target mRNAs are repressed as efficiently by microRNA-binding sites in the 5' UTR as in the 3' UTR. Proc Natl Acad Sci USA 104: 9667-9672, 2007.

55. Nottrott S, Simard MJ and Richter JD: Human let-7a miRNA blocks protein production on actively translating polyribosomes. Nat Struct Mol Biol 13: 1108-1114, 2006.

56. Beilharz TH, Humphreys DT, Clancy JL, Thermann R Martin DI, Hentze MW and Preiss T: MicroRNA-mediated messenger RNA deadenylation contributes to translational repression in mammalian cells. PLoS One 4: e6783, 2009.

57. Johnson SM, Grosshans H, Shingara J, Byrom M, Jarvis R, Cheng A, Labourier E, Reinert KL, Brown D and Slack FJ: Ras is regulated by the let-7 microRNA family. Cell 120: 635-647, 2005.

58. Nelson HH, Christensen BC, Plaza SL, Wiencke JK, Marsit CJ and Kelsey KT: KRAS mutation, KRAS-LCS6 polymorphism, and non-small cell lung cancer. Lung Cancer 69: 51-53, 2010

59. Chin LJ, Ratner E, Leng S, Zhai R, Nallur S, Babar I, Muller RU, Straka E, Su L, Burki EA, et al: A SNP in a let-7 microRNA complementary site in the KRAS 3' untranslated region increases non-small cell lung cancer risk. Cancer Res 68: 8535-8540, 2008.

60. Paranjape T, Heneghan H, Lindner R, Keane FK, Hoffman A, Hollestelle A, Dorairaj J, Geyda K, Pelletier C, Nallur S, et al: A 3'-untranslated region KRAS variant and triple-negative breast cancer: a case-control and genetic analysis. Lancet Oncol 12: 377-386, 2011

61. Lee ST, Chu K, Oh HJ, Im WS, Lim JY, Kim SK, Park CK, Jung KH, Lee SK, Kim M and Roh JK: Let-7 microRNA inhibits the proliferation of human glioblastoma cells. J Neurooncol 102: 19-24, 2010.

62. He XY, Chen JX, Zhang Z, Li CL, Peng QL and Peng HM: The let-7a microRNA protects from growth of lung carcinoma by suppression of k-Ras and c-Myc in nude mice. J Cancer Res Clin Oncol 136: 1023-1028, 2010.

63. Sgarra R, Rustighi A, Tessari MA, Di Bernardo J, Altamura S, Fusco A, Manfioletti G and Giancotti V: Nuclear phosphoproteins HMGA and their relationship with chromatin structure and cancer. FEBS Lett 574: 1-8, 2004
64. Sarhadi VK, Wikman H, Salmenkivi K, Kuosma E, Sioris T, Salo J, Karjalainen A, Knuutila S and Anttila S: Increased expression of high mobility group A proteins in lung cancer. J Pathol 209: 206-212, 2006.

65. Meyer B, Loeschke S, Schultze A, Weigel T, Sandkamp M, Goldmann T, Vollmer E and Bullerdiek J: HMGA2 overexpression in non-small cell lung cancer. Mol Carcinog 46: 503-511, 2007.

66. Abe N, Watanabe T, Suzuki Y, Matsumoto N, Masaki T, Mori T, Sugiyama M, Chiappetta G, Fusco A and Atomi Y: An increased high-mobility group A2 expression level is associated with malignant phenotype in pancreatic exocrine tissue. Br J Cancer 89: 2104-2109, 2003.

67. Miyazawa J, Mitoro A, Kawashiri S, Chada KK and Imai K: Expression of mesenchyme-specific gene HMGA2 in squamous cell carcinomas of the oral cavity. Cancer Res 64: 2024-2029, 2004.

68. Belge G, Meyer A, Klemke M, Burchardt K, Stern C, Wosniok W, Loeschke $\mathrm{S}$ and Bullerdiek J: Upregulation of HMGA2 in thyroid carcinomas: a novel molecular marker to distinguish between benign and malignant follicular neoplasias. Genes Chromosomes Cancer 47: 56-63, 2008.

69. Borrmann L, Wilkening S and Bullerdiek J: The expression of HMGA genes is regulated by their 3 'UTR. Oncogene 20: 4537-4541, 2001

70. Motoyama $\mathrm{K}$, Inoue $\mathrm{H}$, Nakamura $\mathrm{Y}$, Uetake $\mathrm{H}$, Sugihara $\mathrm{K}$ and Mori M: Clinical significance of high mobility group A2 in human gastric cancer and its relationship to let-7 microRNA family. Clin Cancer Res 14: 2334-2340, 2008.

71. Shi G, Perle MA, Mittal K, Chen H, Zou X, Narita M, Hernando E, Lee P and Wei JJ: Let-7 repression leads to HMGA2 overexpression in uterine leiomyosarcoma. J Cell Mol Med 13: 3898-3905, 2009.

72. Mayr C, Hemann MT and Bartel DP: Disrupting the pairing between let-7 and Hmga2 enhances oncogenic transformation. Science 315: 1576-1579, 2007.

73. Albihn A, Johnsen JI and Henriksson MA: Myc in oncogenesis and as a target for cancer therapies. Adv Cancer Res 107: $163-224,2010$.

74. Ruggero D: The role of Myc-induced protein synthesis in cancer. Cancer Res 69: 8839-8843, 2009.

75. Schultz J, Lorenz P, Gross G, Ibrahim S and Kunz M: MicroRNA let-7b targets important cell cycle molecules in malignant melanoma cells and interferes with anchorage-independent growth. Cell Res 18: 549-557, 2008.

76. Johnson CD, Esquela-Kerscher A, Stefani G, Byrom M, Kelnar K, Ovcharenko D, Wilson M, Wang X, Shelton J, Shingara J, et al: The let-7 microRNA represses cell proliferation pathways in human cells. Cancer Res 67: 7713-7722, 2007.

77. Leeman RJ, Lui VW and Grandis JR: STAT3 as a therapeutic target in head and neck cancer. Expert Opin Biol Ther 6: 231-241, 2006.

78. Bowman T, Garcia R, Turkson J and Jove R: STATs in oncogenesis. Oncogene 19: 2474-2488, 2000.

79. Achcar RO, Cagle PT and Jagirdar J: Expression of activated and latent signal transducer and activator of transcription 3 in 303 non-small cell lung carcinomas and 44 malignant mesotheliomas: possible role for chemotherapeutic intervention. Arch Pathol Lab Med 131: 1350-1360, 2007.

80. Ma XT, Wang S, Ye YJ, Du RY, Cui ZR and Somsouk M: Constitutive activation of Stat 3 signaling pathway in human colorectal carcinoma. World J Gastroenterol 10: 1569-1573, 2004.

81. Wang Y, Lu Y, Toh ST, Sung WK, Tan P, Chow P, Chung AY, Jooi LL and Lee CG: Lethal-7 is down-regulated by the hepatitis $B$ virus $x$ protein and targets signal transducer and activator of transcription 3. J Hepatol 53: 57-66, 2010.

82. Bronner C, Achour M, Arima Y, Chataigneau T, Saya H and Schini-Kerth VB: The UHRF family: oncogenes that are drugable targets for cancer therapy in the near future? Pharmacol Ther 115: 419-434, 2007.

83. Robinson PA and Ardley HC: Ubiquitin-protein ligases. J Cell Sci 117: 5191-5194, 2004.

84. Arima Y, Hirota T, Bronner C, Mousli M, Fujiwara T, Niwa S, Ishikawa $\mathrm{H}$ and Saya $\mathrm{H}$ : Down-regulation of nuclear protein ICBP90 by p53/p21Cip1/WAF1-dependent DNA-damage checkpoint signals contributes to cell cycle arrest at G1/S transition. Genes Cells 9: 131-142, 2004.

85. He X, Duan C, Chen J, Ou-Yang X, Zhang Z, Li C and Peng H: Let-7a elevates p21(WAF1) levels by targeting of NIRF and suppresses the growth of A549 lung cancer cells. FEBS Lett 583: 3501-3507, 2009. 